\title{
HUBUNGAN KONSUMSI KOPI DENGAN FREKUENSI DENYUT NADI PADA MAHASISWA PROGRAM STUDI PENDIDIKAN DOKTER UNIVERSITAS MALIKUSSALEH TAHUN 2019
}

\author{
Nora Maulina ${ }^{1}$, Muhammad Sayuti ${ }^{2}$, Badra Hasana Said $^{3}$ \\ ${ }^{1}$ Bagian Ilmu Fisiologi, Fakultas Kedokteran, UniversitasMalikussaleh \\ ${ }^{2}$ Bagian Ilmu Bedah, Fakultas Kedokteran, UniversitasMalikussaleh \\ ${ }^{3}$ Program Studi Pendidikan Dokter, FakultasKedokteran, UniversitasMalikussaleh \\ Corresponding author: nora.maulina@gmail.com
}

\begin{abstract}
Abstrak
Denyut nadi adalah jumlah denyutan jantung per menit dengan berbagai faktor yang mempengaruhi, termasuk kafein. Kafein (1,3,7-trimethylpurine-2,6-dione) banyak terkandung di dalam kopi, yang merupakan salah satu minuman yang paling banyak dikonsumsi di dunia, termasuk di kalangan mahasiswa. Meskipun sudah diteliti berpuluh-puluh tahun, efek kafein terhadap kesehatan kardiovaskular masih belum jelas.Penelitian ini bertujuan untuk mengetahui hubungan antara riwayat konsumsi kopi selama satu tahun terakhir dengan frekuensi denyut nadi yang diukur menggunakan metode palpasi arteri radialis pada mahasiswa Program Studi Pendidikan Dokter (PSPD) Universitas Malikussaleh tahun 2019. Penelitian ini merupakan penelitian analitik observasional melalui pendekatan cross sectional. Analisis statistik menggunakan uji Kolmogorov-Smirnov.Sampel pada penelitian ini adalah 73 mahasiswa yang telah memenuhi syarat inklusi dan eksklusi. Hasil penelitian pada responden didapatkan sebanyak $72,6 \%$ merupakan pengonsumsi kopi (4,1\% konsumsi harian, 21,9\% mingguan, dan 46,6\% bulanan) dan 27,4\% bukan pengonsumsi, sementara frekuensi denyut nadi normal sebanyak $90,4 \%$, bradikardia $6,8 \%$, dan takikardia 2,7\%. Analisis statistik bivariat mendapatkan nilai $\mathrm{p}>0,05$ sehingga dapat disimpulkan bahwa tidak terdapat hubungan antara konsumsi kopi dengan frekuensi denyut nadi pada mahasiswa PSPD Universitas Malikussaleh tahun 2019.
\end{abstract}

Kata kunci: denyut-nadi; konsumsi-kopi; mahasiswa-kedokteran

\section{Association between Coffee Consumption and Pulse on Medical Students of Malikussaleh University in 2019}

\begin{abstract}
Pulse is the number of heart beat per minute with various influencing factors, including caffeine. Caffeine (1,3,7-trimethylpurine-2,6-dione) is contained in large quantity in coffee, which is one of the most consumed drinks in the world, including among college students. Even though it has been studied for decades, the effect of caffeine on cardiovascular health is still unclear. This study aims to determine the association between history of coffee consumption over the past year and pulse using
\end{abstract}


the radial artery palpation method on medical students of Malikussaleh University in 2019. This is an observational analytic study with cross sectional approach. Kolmogorov-Smirnov test was used for statistical analysis. The sample in this study were 73 students who had fulfilled the inclusion and exclusion requirements. The results showed that $72,6 \%$ of respondents were coffee drinkers $(4,1 \%$ daily, $21,9 \%$ weekly, and $46,6 \%$ monthly consumption) and $27,4 \%$ were non drinkers, while, in term of pulse, $90,4 \%, 6,8 \%$, and $2,7 \%$ were normal, bradycardia, and tachycardia, respectively. Bivariate analytical statistic result showed $p$ value $>0,05$ thus it can be concluded that there is no association between coffee consumption and pulse on medical students of Malikussaleh University in 2019.

Keywords: coffee-consumption; medical-students; pulse

\section{PENDAHULUAN}

Denyut jantung (heart rate/HR) atau denyut nadi (pulse) adalah jumlah denyutan jantung per menit. ${ }^{1}$ Jumlah HR per menit yang normal berkisar antara 60 sampai 100 ketika istirahat. Namun, hasil pengukuran bervariasi tergantung pada waktu dilakukannya dan apa yang dikerjakan pasien sebelum proses pengukuran. Denyut jantung akan lebih rendah jika pasien dalam keadaan beristirahat daripada ketika pasien melakukan suatu hal seperti berjalan. ${ }^{2}$ Keadaan ini disebabkan karena peningkatan kebutuhan tubuh akan energi ketika beraktivitas sehingga jantung, yang berfungsi mengedarkan oksigen ke seluruh tubuh untuk kebutuhan pembentukan energi, akan bekerja lebih keras. ${ }^{3}$ Selain aktivitas ada beberapa faktor lain yang dapat memengaruhi HR.

Geethavani et al. dari hasil penelitiannya menemukan bahwa terdapat hubungan positif antara denyut nadi dan konsumsi kafein. Mereka mendapatkan bahwa terjadi peningkatan denyut nadi sebesar 4,4beat per minute (bpm) dari 72,9 bpm menjadi 77,3 bpm setelah 60 menit ingesti $5 \mathrm{mg} / \mathrm{kgBB}$ kafein. Hal ini disebabkan karena kafein akan meningkatan kekakuan aorta dan pembuluhpembuluh darah besar akibat produksi angiotensin II dan katekolamin, kemungkinan adrenalin. ${ }^{4}$ Kafein merupakan zat psikoaktif yang banyak dikandung dalam teh, minuman ringan, coklat, dan kopi. ${ }^{5}$

Kopi merupakan salah satu minuman yang banyak dikonsumsi oleh penduduk dunia. Menurut International Coffee Organization (ICO), sebanyak 9,7 juta ton kopi dikonsumsi di seluruh dunia pada 2017/2018. Angka tersebut menunjukkan peningkatan dari tahun-tahun sebelumnya yaitu 9,48 juta ton pada 2016/2017, 9,32 juta ton pada 2015/2016, dan 9,09 juta ton pada 2014/2015. Dari data tersebut dapat 
dilihat bahwa tingkat konsumsi kopi dunia terus meningkat dari tahun ke tahun. ${ }^{6}$

Menurut Direktorat Jenderal Perkebunan Kementerian Pertanian Indonesia, estimasi produksi total kopi Indonesia pada 2017 adalah 637.539 ton. Sumatera Selatan, Lampung, dan Sumatera Utara menempati 3 urutan teratas sebagai provinsi penghasil kopi Indonesia. Sementara itu, Aceh menempati posisi keempat sebagai provinsi penghasil kopi terbanyak pada tahun 2017 di Indonesia yaitu sebanyak 46.828 ton. $^{7}$

Masyarakat Aceh sangat gemar mengonsumsi kopi. Di kota Lhokseumawe, contohnya, kegemaran masyarakat dalam mengonsumsi kopi dapat dilihat dari banyaknya warung kopi atau coffee shop yang berjejer di sepanjang jalan dari dan/atau menuju kota. ${ }^{8}$ Kegemaran mengonsumsi kopi di Aceh sudah bukan hanya budaya orang tua saja namun sudah milik semua golongan, termasuk mahasiswa. ${ }^{9}$

Tingkat konsumsi kopi di kalangan mahasiswa kedokteran sangat tinggi. Sebuah studi deskriptif cross-sectional di Bali menunjukkan dari 491 mahasiswa Program Studi Pendidikan Dokter (PSPD) yang bersedia menjadi responden, sebanyak 91,9\% merupakan pengonsumsi kopi. Proporsi frekuensi konsumsi kopi diantara responden yang meminum kopi secara harian yaitu 1 kali sehari (69,2\%), 2 kali sehari (23,1\%), dan 3 kali sehari $(7,7 \%) .^{10}$

Pada penelitian yang sama didapatkan berbagai efek negatif konsumsi kopi terhadap tubuh. Sebanyak 71,6\% konsumen mengalami efek samping dari kopi seperti kesulitan tidur (50,5\%), palpitasi $(33,7 \%)$, peningkatan frekuensi urinasi $(31,9 \%)$, sakit kepala $(20,2 \%)$, tremor $(10,9 \%)$, serta gejala lain. ${ }^{10}$

Echeverri et al. (2017)dalam penelitiannya mendapatkan hasil bahwa efek akut konsumsi kopi juga berdampak pada kekakuan arteri. Terdapat peningkatan signifikan brachial-systolic-blood-pressure sebesar 3,9 dan 3,8 mmHg, brachialdiastolic-blood-pressure sebesar 4,1 dan 3,2 mmHg, mean-arterial pressure (MAP) sebesar 4 dan 3,3 mmHg, serta central-systolic-blood-pressure sebesar 5,8 dan 7,6 mmHg, brachial augmentation index (AIx) 9,9 dan 12,3\%, aortic AIx 5,1 dan 6,3\% setelah 30 dan 60 menit konsumsi kopi. Peneliti menyimpulkan bahwa konsumsi kopi meningkatkan kekakuatan arteri perifer dengan meningkatnya tonus arteri distal tanpa perubahan kekakuan sentral. Meskipun demikian, peneliti belum bisa menyimpulkan apakah perubahan kekakuan arteri tersebut dapat memengaruhi kesehatan populasi secara keseluruhan. ${ }^{11}$ 
Selain efek negatif yang dapat ditimbulkan, konsumsi kopi juga didapatkan memiliki dampak positif bagi tubuh. Sebuah studi cohort menunjukkan bahwa konsumsi kopi golongan menengah ( $\geq 2-4$ gelas/hari) dan tinggi ( $\geq 5-9$ gelas/hari) diasosiasikan dengan total mortalitas signifikan lebih rendah dibandingkan dengan golongan rendah/tidak mengonsumsi kopi. ${ }^{12}$ Hal ini didukung oleh Dietary Guidelines Advisory Committee yang menyimpulkan bahwa konsumsi kopi golongan menengah (3-5 gelas/hari atau kafein $400 \mathrm{mg} /$ hari) dapat menjadi bagian dari diet sehat. $^{13}$

Efek pasti kopi terhadap kesehatan kardiovaskular tetap kontroversial meskipun telah diteliti selama lebih dari 4 dekade. ${ }^{14}$ Hal ini tentu menjadi masalah karena denyut jantung merupakan faktor risiko independen terhadap berbagai kejadian gangguan kardiovaskular dan mortalitas. ${ }^{15}$

Aune et al. menemukan bahwa setiap 10 bpm peningkatan denyut jantung, terdapat risiko relatif (RR) sebesar 1,07 untuk penyakit jantung koroner, 1,09 untuk kematian jantung mendadak, 1,18 untuk gagal jantung, 1,06 untuk stroke total, 1,15 untuk cardiovascular disease (CVD), 1,14 untuk kanker total, dan 1,17 untuk allcause mortality. Dari berbagai gangguan/penyakit yang diteliti tersebut, semua menunjukkan peningkatan risiko kejadian seiring dengan peningkatan HR. ${ }^{15}$

Berdasarkan kentalnya kultur masyarakat Aceh dalam mengonsumsi kopi khususnya di Kota Lhokseumawe dan besarnya prevalensi pengonsumsi kopi dikalangan mahasiswa kedokteran serta belum jelasnya efek jangka panjang konsumsi kopi terhadap frekuensi denyut nadi maka peneliti tertarik untuk melakukan penelitian mengenai hubungan konsumsi kopi dengan denyut nadi di kalangan mahasiswa PSPD Universitas Malikussaleh.

\section{METODE}

\section{Desain}

Penelitian ini menggunakan metode analitik observasional dengan pendekatan cross sectional.Penelitian ini akan dilakukan di Kampus Fakultas Kedokteran Universitas Malikussaleh, Cunda, Lhokseumawe. 


\section{Populasi dan sampel}

Populasi dalam penelitian ini adalah seluruh Mahasiswa PSPD Universitas Malikussaleh pada tahun 2019 sebanyak 233 orang.Sampel dalam penelitian ini adalah seluruh Mahasiswa PSPD Universitas Malikussaleh yang sedang aktif berkuliah dan memenuhi kriteria inklusi dan eksklusi.

Kriteria inklusi:

1. Bersedia dijadikan sampel dalam penelitian ini.

Kriteria eksklusi:

1. Tidak hadir selama pengambilan data.

2. Memiliki riwayat gangguan jantung, paru, ginjal, hati, atau tiroid.

3. Sedang demam/tidak enak badan.

4. Sedang mongonsumsi obat-obatan.

5. Perokok.

6. Pengonsumsi minuman beralkohol.

7. Dalam 24 jam terakhir mengonsumsi makanan atau minuman yang mengandung kafein dengan kopi sebagai pengecualian.

\section{Teknik pengambilan sampel}

Teknik pengambilan sampel dalam penelitian ini menggunakan teknik non probability sampling dengan carapurposive sampling.Besar sampel dalam penelitian ini adalah seluruh jumlah populasi yang memenuhi kriteria inklusi dan eksklusi sebanyak 73 orang.

\section{Variabel}

Variabel dalam penelitian ini:

1. Variabel dependen: frekuensi denyut nadi

2. Variabel Independen: konsumsi kopi

\section{Sumber data dan instrumen}

Sumber data dalam penelitian ini diperoleh dari

1. Data primer hasil pengukuran palpasi antebrachii pada saat proses pengambilan data.

2. Data primer dari hasil pengisian kuesionerpada saat proses pengambilan data.

Instrumen yang digunakan dalam penelitian ini adalah kuesioner. 


\section{Analisis data}

Analisis data yang dilakukan:

1. Analisis univariat

Analisis univariat dalam penelitian ini dilakukan terhadap variabel konsumsi kopi serta frekuensi denyut nadi.

\section{Analisis bivariat}

Analisis bivariat dalam penelitian ini bertujuan untuk menghubungkan konsumsi kopi dengan frekuensi denyut nadi menggunakan uji Kolmogorov-Smirnov.Jika berdasarkan hasil uji didapatkan nilai $\mathrm{p}<0,05$, maka terdapat hubungan yang bermakna antara kedua variabel, sedangkan jika nilai $\mathrm{p}>0,05$ maka tidak terdapat hubungan yang bermakna antara kedua variabel.

\section{HASIL PENELITIAN}

Pada penelitian didapatkan hasil:

Tabel 1. Distribusi responden menurut jenis kelamin

\begin{tabular}{ccc} 
Jenis Kelamin & Frekuensi (n) & Persentase (\%) \\
\hline Laki-laki & 16 & 21,9 \\
Perempuan & 57 & 78,1 \\
\hline Total & 73 & 100,0
\end{tabular}

Sumber: Data primer, 2019

Tabel 1.menunjukkanbahwa distribusi frekuensi responden menurut jenis kelamin terbanyak yaitu perempuan dengan jumlah 57 orang $(78,1 \%)$ kemudian laki-laki dengan jumlah 16 orang $(21,9 \%)$.

Tabel 2. Distribusi responden menurut umur

\begin{tabular}{ccc}
\hline Umur & Frekuensi (n) & Persentase (\%) \\
\hline 17 & 1 & 1,4 \\
18 & 15 & 20,5 \\
19 & 23 & 31,5 \\
20 & 29 & 39,7 \\
21 & 4 & 5,5 \\
22 & 1 & 1,4 \\
\hline Total & 73 & 100,0
\end{tabular}

Sumber: Data primer, 2019 
Tabel 2. menunjukkan bahwa distribusi frekuensi responden menurut umur terbanyak yaitu 20 tahun sebanyak 29 orang (39,7\%) dan paling sedikit 17 serta 22 tahun dengan masing-masing 1 orang $(1,4 \%)$.

Tabel 3. Distribusi tingkat konsumsi kopi responden

\begin{tabular}{ccc}
\hline Konsumsi Kopi & Frekuensi (n) & Persentase (\%) \\
\hline Harian & 3 & 4,1 \\
Mingguan & 16 & 21,9 \\
Bulanan & 34 & 46,6 \\
Tidak pernah & 20 & 27,4 \\
\hline Total & 73 & 100,0
\end{tabular}

Sumber: Data primer, 2019

Tabel 3. Menunjukkan bahwa distribusi tingkat konsumsi kopi responden terbanyak yaitu kategori bulanan (1-3 kali/bulan) sebanyak 34 orang $(46,6 \%)$ dan paling sedikit harian ( $\geq 1 \mathrm{kali} /$ hari) sebanyak 3 orang $(4,1 \%)$.

Tabel 4. Distribusi tingkat denyut nadi responden

\begin{tabular}{ccc}
\hline Denyut Nadi & Frekuensi (n) & Persentase (\%) \\
\hline Bradikardia $(<60 \mathrm{bpm})$ & 5 & 6,8 \\
Normal $(60-100 \mathrm{bpm})$ & 66 & 90,4 \\
Takikardia $(>100 \mathrm{bpm})$ & 2 & 2,7 \\
\hline Total & 73 & 100,0 \\
\hline
\end{tabular}

Sumber: Data primer, 2019

Tabel 4.menunjukkan bahwa distribusi tingkat denyut nadi responden terbanyak yaitu normal (60-100 bpm) sebanyak 66 orang $(90,4 \%)$ dan paling sedikit takikardia (>100 bpm) sebanyak 2 orang $(2,7 \%)$.

Tabel 5.Hubungan Konsumsi Kopi dengan Denyut Nadi

\begin{tabular}{|c|c|c|c|c|c|c|c|c|c|}
\hline \multirow{3}{*}{$\begin{array}{c}\text { Konsumsi } \\
\text { Kopi }\end{array}$} & \multicolumn{6}{|c|}{ Denyut Nadi } & \multirow{2}{*}{\multicolumn{2}{|c|}{ Total }} & \multirow{3}{*}{ p value } \\
\hline & \multicolumn{2}{|c|}{$\begin{array}{c}\text { Bradikardia } \\
\text { (<60 bpm) }\end{array}$} & \multicolumn{2}{|c|}{$\begin{array}{c}\text { Normal } \\
(60-100 \\
\text { bpm) }\end{array}$} & \multicolumn{2}{|c|}{$\begin{array}{l}\text { Takikardia } \\
\text { (>100 bpm) }\end{array}$} & & & \\
\hline & $\mathbf{n}$ & $\%$ & $\mathbf{n}$ & $\%$ & $\mathbf{n}$ & $\%$ & $\mathbf{n}$ & $\%$ & \\
\hline Harian & 0 & 0 & 2 & 3 & 1 & 50 & 3 & 4,1 & \\
\hline Mingguan & 2 & 40 & 13 & 19,7 & 1 & 50 & 16 & 21,9 & \\
\hline Bulanan & 3 & 60 & 31 & 47 & 0 & 0 & 34 & 46,6 & 0,931 \\
\hline $\begin{array}{l}\text { Tidak } \\
\text { pernah }\end{array}$ & 0 & 0 & 20 & 30,3 & 0 & 0 & 20 & 27,4 & \\
\hline Total & 5 & 100 & 66 & 100 & 2 & 100 & 73 & 100 & \\
\hline
\end{tabular}

Sumber: Data primer, 2019 
Tabel 5.berisi hasil uji Kolmogorov-Smirnov menunjukkan $p$ value sebesar $0,931(\alpha=0,005)$ yang berarti Ho diterima atau tidak terdapat hubungan antara konsumsi kopi dengan frekuensi denyut nadi pada mahasiswa PSPD Universitas Malikussaleh tahun 2019.

\section{PEMBAHASAN}

\section{Konsumsi kopi}

Hasil penelitian didapatkan bahwa dari 73 total responden, terdapat jumlah pengonsumsi kopi harian sebanyak 3 orang (4,1\% dari keseluruhan atau 5,7\% dari populasi pengonsumsi kopi), mingguan sebanyak 16 orang (21,9\% dari keseluruhan atau 30,2\% dari populasi pengonsumsi kopi), dan bulanan sebanyak 34 orang (46,6\% dari keseluruhan atau $64,2 \%$ dari populasi pengonsumsi kopi), sedangkan yang tidak atau hampir tidak pernah mengonsumsi sebanyak 20 orang $(27,4 \%$ dari keseluruhan).

Hasil penelitian menunjukkan bahwa, secara umum, sebanyak $73 \%$ responden merupakan pengonsumsi kopi dan 27\% bukan pengonsumsi kopi. Hal ini sejalan dengan penelitian Khairani dimana, dari 100 responden pada penelitiannya, $67 \%$ merupakan pengonsumsi kopi sementara 33\% bukan pengonsumsi kopi. ${ }^{16}$ Demikian juga dengan penelitian Liveina dan Artini yang menunjukkan bahwa sebanyak $91,9 \%$ responden penelitian mereka merupakan pengonsumsi kopi. ${ }^{10}$

Gambaran konsumsi kopi harian dan non harian penelitian ini sejalan dengan penelitian Liveina dan Artini.Dalam penelitiannya mereka mendapatkan hanya 7\% dari pengonsumsi kopi yang mengonsumsi harian dan sisanya sebanyak 93\% merupakan pengonsumsi non harian di populasi serupa (mahasiswa PSPD). Proporsi pengonsumsi kopi harian terbilang sangat rendah dibandingkan populasi total pengonsumsi kopi. ${ }^{10}$

Banyaknya jumlah konsumsi kopi di kalangan pelajar Indonesia, khususnya pada mahasiswa PSPD, dapat disebabkan oleh efek kopi sebagai agen stimulan. Para pelajar memanfaatkan kopi sebagai penambah energi dan penghilang kantuk khususnya saat menjelang ujian. ${ }^{10}$

\section{Frekuensi denyut nadi}

Hasil penelitian didapatkan bahwa frekuensi denyut nadi responden terbanyak yaitu dalam kategori normal (60-100 bpm) sebanyak 66 orang $(90,4 \%)$, 
diikuti bradikardia $(<60 \mathrm{bpm})$ sebanyak 5 orang $(6,8 \%)$, dan paling sedikit takikardia (>100 bpm) sebanyak 2 orang (2,7\%). Hal ini menunjukkan bahwa sebagian besar responden mempunyai denyut nadi yang normal $(90,4 \%)$ sementara bradikardia dan takikardia hanya sedikit $(9,6 \%)$.Sekalipun pengambilan data diambil hanya melalui proses palpasi, tidak ada responden dengan data yang ambigu. Perbedaan hasil pengukuran pertama, kedua, dan ketiga dari tiap-tiap responden tidak terpaut jarak yang jauh dan selalu dalam kategori yang sama.

Hasil penelitian tentang gambaran frekuensi denyut nadi ini sejalan dengan penelitian Sonbay, sekalipun dengan desain penelitian yang berbeda. Pada penelitiannya dengan populasi serupa (mahasiswa PSPD), didapatkan sebagian besar yaitu $95,8 \%$ responden tergolong dalam kategori denyut nadi normal. ${ }^{17}$

Banyak faktor yang memengaruhi denyut nadi seperti gangguan jantung, gangguan hati, gangguan ginjal, gangguan tiroid, peningkatan suhu tubuh, konsumsi kafein, konsumsi obat-obatan, merokok, dan konsumsi alkohol. ${ }^{18,19,20,21}$ Dalam penelitian ini, faktor-faktor tersebut menjadi faktor eksklusi untuk mengurangi kemungkinan bias. Hal ini menyebabkan responden terhindar dari banyak faktor yang dapat mempengaruhi frekuensi denyut nadi mereka, sehingga mayoritas hasil yang didapat adalah normal.

\section{Konsumsi kopi dan frekuensi denyut nadi}

Hasil penelitian menunjukkan bahwa tidak terdapat hubungan antara konsumsi kopi dengan frekuensi denyut nadi dan tidak terbukti bernilai secara statistik $(\mathrm{p}>0,05)$.

Hal ini dapat disebabkan karena efek kafein yang dikandung di dalam kopi lebih dominan bersifat sementara (akut) dalam hal pengaruhnya terhadap frekuensi denyut nadi. ${ }^{4}$ Sementara untuk efek jangka panjang kopi terhadap frekuensi denyut nadi selama setahun tidak cukup besar.

Pada manusia kafein dengan cepat dan seluruhnya diabsorbsi setelah ingesti.Setelah diabsorbsi kafein kemudian melewati sawar darah otak, plasenta, dan testikel. Rute metabolisme utamanya (70-80\%) adalah melalui $\mathrm{N}-3$ demethylation menjadi paraxanthine atau 1,7-dimethylxanthine atau 17X yang dikatalisasi oleh CYP1A2 di hati. Metabolit utama lainnya adalah theophylline dan theobromine. Sebagian besar (95\%) caffeine clearance dimetabolisme oleh CYP1A2 sementara sisanya oleh CYP3A4, xanthine oxidase, dan N-855 acetyltransferase 
$2<$ sup $>22</$ sup $>$ (EFSA NDA Panel (EFSA Panel on Dietetic Products, 2015). Kafein mempunyai waktu paruh sekitar 4 jam dengan rentang 2-8 jam. Paraxanthine, theophylline, dan theobromine kemudian dimetabolisme lebih lanjut dan diekskresikan ke dalam urin. ${ }^{22}$

Penelitian-penelitian sebelumnya menunjukkan hasil yang berbeda-beda tentang hubungan konsumsi kopi atau kafein dengan denyut nadi atau jantung.Geethavani et al.dari hasil penelitiannya menunjukkan bahwa terdapat hubungan positif antara denyut nadi dan konsumsi kafein. Terdapat peningkatan denyut nadi sebesar 4,4 bpm dari 72,9 bpm menjadi 77,3 bpm setelah 60 menit ingesti $5 \mathrm{mg} / \mathrm{kgBB}$ kafein kapsul dibandingkan dengan placebo. Hal ini disebabkan karena kafein akan meningkatan angiotensin II yang merupakan vasokonstriktor kuat. Angiotensin II kemudian secara ampuh meningkatkan pelepasan katekolamin oleh sistem saraf tepi, yang kemudian berkontribusi pada proses vasokonstriksi dan penahanan natrium oleh angiotensin II. Katekolamin juga dapat menyebabkan peningkatan denyut jantung. ${ }^{4}$

Sementara itu, menurut hasil penelitian Kumar dan Verma pada 80 relawan, didapatkan peningkatan tekanan darah sistolik serta penurunan denyut jantung setelah pemberian kopi pada kelompok kontrol dan kasus. Hal ini menunjukkan bahwa kafein teringesti mungkin tidak menimbulkan efek melalui sistem saraf simpatis karena stimulasi simpatis akan menyebabkan sekresi norepinephrine dengan efek kronotropik dan inotropik positif yang meningkatkan denyut jantung dan kekuatan pompa jantung. Namun demikian, penelitian tersebut tidak dapat menentukan mekanisme yang menyebabkan terjadinya peningkatan tekanan darah sistolik pada kedua kelompok. $^{23}$

\section{KESIMPULAN \& SARAN}

\section{Kesimpulan}

Kesimpulan hasil penelitian:

1. Gambaran responden pengonsumsi kopi sebanyak $73 \%$ dengan proporsi terbanyak yaitu kategori konsumsi bulanan (1-3 kali/bulan) sebanyak 64,2\% (46,6\% dari keseluruhan) dan paling sedikit harian ( $\geq 1 \mathrm{kali} / \mathrm{hari})$ sebanyak $5,7 \%$ (4,1\% dari keseluruhan).

2. Gambaran frekuensi denyut nadi terbanyak adalah normal sebanyak $90,4 \%$ dan paling sedikit takikardia sebanyak $2,7 \%$. 
3. Tidak terdapat hubungan antara konsumsi kopi dan frekuensi denyut nadi pada mahasiswa PSPD Universitas Malikussaleh tahun 2019.

\section{Saran}

Saran dari penelitian:

1. Bagi peneliti selanjutnya agar dapat,

a. menggunakan kuesioner mengenai riwayat konsumsi kopi, mencakup tidak hanya kuantitas konsumsi kopi rutin dalam 1 tahun terakhir namun juga berapa lama telah rutin mengonsumsi kopi, jenis kopi yang dikonsumsi, dan cara penyajian kopi tersebut.

b. menggunakan pengukuran denyut nadi dengan alat yang mempunyai sensitivitas dan spesifisitas lebih tinggi.

c. mengambil populasi dengan heterogenitas dan kuantitas yang lebih besar.

2. Bagi pengonsumsi kopi agar dapat mengikuti saran yang telah dikeluarkan badan-badan pengawas makanan mengenai kuantitas dan kualitas kopi yang akan dikonsumsi untuk mendapatkan manfaaat yang optimal

\section{DAFTAR PUSTAKA}

1. American Heart Association. All About Heart Rate (Pulse) [Internet]. 2018. Available from: http://www.heart.org/HEARTORG/Conditions/HighBloodPressure/GettheFact sAboutHighBloodPressure/All-About-Heart-Rate-

Pulse UCM 438850 Article.jsp

2. British Heart Foundation. Your heart rate [Internet]. 2014. p. 1. Available from: https://www.bhf.org.uk/-/media/files/publications/medical-informationsheets/your-heart-rate-is23.pdf

3. Barrett KE, Barman SM, Boitano S, Brooks HL. Ganong's Review of Medical Physiology. 2016. 1-763 p.

4. Geethavani G, Rameswarudu M, Reddy R. Effect of Caffeine on Heart Rate and Blood Pressure. Int J Sci Res Publ. 2014;4(2):1-4.

5. Zucconi S, Valpato C, Adinolfi F, Gandini E, Gentile E, Loi LF. Gathering consumption data on specific consumer groups of energy drinks [Internet]. 2013.

Available from: https://efsa.onlinelibrary.wiley.com/doi/epdf/10.2903/sp.efsa.2013.EN-394

6. International Coffee Organization. World coffee consumption [Internet]. International Coffee Organization; 2017. Available from: http://www.ico.org/prices/new-consumption-table.pdf

7. Direktorat Jenderal Perkebunan. Statistik Perkebunan Indonesia [Internet]. Direktorat Jenderal Perkebunan; 2017. Available from: http://ditjenbun.pertanian.go.id/tinymcpuk/gambar/file/statistik/2017/Kopi- 
2015-2017.pdf

8. Meutia S, Bakhtiar, Lia PN. Analisis positioning product kopi gayo berdasarkan persepsi konsumen coffee shop raja kupi aceh, black castle, dan station coffee di kota lhokseumawe. Semin Nas Tek Ind [SNTI2017]. 2017;341-8.

9. Hayati N. Eksistensi Penggunaan Wi-Fi Di Warung Kopi Di Kota Banda Aceh. J Al-Ijtimaiyyah. 2015;1(1):64-72.

10. Liveina, Artini. Pola konsumsi dan efek samping minuman mengandung kafein pada mahasiswa program studi pendidikan dokter Fakultas Kedokteran Universitas Udayana. 2014;3(4):1-12.

11. Echeverri D, Pizano A, Montes R, Forcada P. Acute effect of coffee consumption on arterial stiffness, evaluated using an oscillometric method. Artery Res. 2017; 17:16-32.

12. Je Y, Giovannucci E. Coffee consumption and total mortality: A meta-analysis of twenty prospective cohort studies. Br J Nutr. 2014;111(7):1162-73.

13. Dietary Guidelines Advisory Committee. Scientific Report of the 2015 Dietary Guidelines Advisory Committee. Vol. 53, Washington (DC): USDA and US Department of Health and Human Services. 2015. p. 1689-99.

14. Rebello SA, van Dam RM. Coffee Consumption and Cardiovascular Health: Getting to the Heart of the Matter. Curr Cardiol Rep. 2013;15(10):403.

15. Aune D, Sen A, Hartaigh B, Janszky I, Romundstad PR, Tonstad S. Resting heart rate and the risk of cardiovascular disease , total cancer, and all-cause mortality - A systematic review and dose-response meta-analysis of prospective studies. Nutr Metab Cardiovasc Dis [Internet]. 2017;27(6):50417. Available from: http://dx.doi.org/10.1016/j.numecd.2017.04.004

16. Khairani M. Pengaruh Minuman Kopi Terhadap Kualitas Tidur Mahasiswa/i Angkatan 2015 Fakultas Kedokteran Universitas Sumatera Utara. Universitas Sumatera Utara; 2017.

17. Sonbay CL. Gambaran Tingkat Kecemasan, Tekanan Darah dan Denyut Nadi Pada Saat Tidak Ujian dan Sesaat Sebelum Ujian Pada Mahasiswa Fakultas Kedokteran Widya Mandala Surabaya. Universitas Katolik Widya Mandala; 2016.

18. Hall JE. Guyton and Hall Textbook of Medical Physiology. 13th ed. Elsevier Inc.; 2016.

19. WebMD. Caffeine [Internet]. WebMD; 2019. Available from: https://www.webmd.com/vitamins/ai/ingredientmono-979/caffeine

20. Papathanasiou G, Mamali A, Papafloratos S, Zerva E. Effects of Smoking on Cardiovascular Function: The Role of Nicotine and Carbon Monoxide. Heal Sci J. 2014;8(2):274-90.

21. Ryan JM, Howes LG. Relations between alcohol consumption, heart rate, and heart rate variability in men. Heart. 2002;88:641-2.

22. EFSA NDA Panel (EFSA Panel on Dietetic Products N and A. Scientific Opinion on the safety of caffeine. EFSA J. 2015; volume(issue): 112.

23. Kumar P, Verma DK. Effect of coffee on blood pressure and electrocardiographic changes in young and elderly healthy subjects. Natl J Med Res. 2013;3(1):53-5. 